Article

\title{
Impact of Scientific Scrutiny after the 2016 Braunsbach Flash Flood on Flood-Risk Management in the State of Baden-Württemberg, Germany
}

\author{
Antje Witting ${ }^{1,2, *}$, Frederik Brandenstein ${ }^{3}{ }^{-},{\text {Christiane } \text { Zarfl }^{1} \text { and Ana Lucía }}^{1}{ }^{1}$ \\ 1 Center for Applied Geoscience, Eberhard Karls University of Tübingen, 72074 Tübingen, Germany; \\ christiane.zarfl@uni-tuebingen.de (C.Z.); a.lucia.vela@gmail.com (A.L.) \\ 2 Department of Politics \& Public Administration, University of Konstanz, 78464 Konstanz, Germany \\ 3 NRW-Forschungskolleg Future Water, Rhein Ruhr Institute for Social Research and Policy Consulting (RISP), \\ University of Duisburg-Essen, 47057 Duisburg, Germany; frederik.brandenstein@uni-due.de \\ * Correspondence: antje.witting@uni-konstanz.de
}

Received: 28 January 2020; Accepted: 10 April 2020; Published: 18 April 2020

\begin{abstract}
This paper presents interdisciplinary research focusing on the municipality of Braunsbach in the German state of Baden-Württemberg, where, in May 2016, a flash flood attracted media attention and scientific scrutiny that highlighted the fact that certain aspects of flood risk were overlooked during earlier assessments conducted by the municipality, such as sediment transport. Using a network analysis and a focus-group discussion, we traced the flow of knowledge through the reported interactions between governmental, private, and academic actors in the two and a half years after the event. From our analysis, we learned that the extreme event attracted scientists to the formal and informal assessment of the hazard and the associated damages. Most importantly, we found conditions under which scientific scrutiny is not detached from but becomes integrated in a governance setting. While it is through this process that sediment transport has become an integral part of flood-risk management in Baden-Württemberg, with an evident impact on the measures already implemented, the impact of morphological changes, as well as large wood and sediment transport, have not been factored into the risk assessment as of yet. These variations in scientific impact on the assessment can be explained by decision biases that can occur when decision makers are under pressure to tackle vulnerabilities and thus lack the time to deliberate in a way that uses all the available evidence.
\end{abstract}

Keywords: water governance; flood-risk management; agenda setting; public attention

\section{Introduction}

Climate change is a global phenomenon that gives rise to an increasing number of localized water-related extreme events. "As dramatic and damaging as these events are, disasters are low priority public problems until the moment they strike" [1] (p. 221). In theory, a water-related disaster, such as a severe flood, attracts the attention of policy entrepreneurs. In an attempt to place a specific issue on the political agenda, these entrepreneurs try to couple the available knowledge about an issue (the problem stream), strategies to respond to the issue (the policy stream), and the politics involved in the formal and informal agreements on these strategies and their implementation (the political stream). In this way, entrepreneurs help to define flood-related risks and to identify the experts and interested parties that should be represented in the decision process about the most effective measures to mitigate them [1-4]. Likewise, such events can attract the resources that entrepreneurs need to facilitate the process [5]. Through brokering the coupling of the three aforementioned streams, entrepreneurs force the dissemination of the available expertise in a wider network [6]. This development can open a 
window of opportunity during which collaborations that drive rapid changes in existing policies and practices become possible [7,8]. See for examples Kemper's and Partzsch's contribution to this special issue [9]. Several other examples of these dynamics between the recognition of a problem and the need for collaboration to increase the odds of successfully addressing this problem can be found in recent water issues [10,11]. An example of the strategies that can emerge from collaborations can be found in Tuson and Triebskorn's contribution to this special issue [12]. However, it has also been noted that the "interests in disasters and possible responses to disasters (after a short-lived spike of attention) fade rather quickly. The next disaster rekindles interest, and the cycle repeats" [1] (p. 221).

The socioecological resilience of the new policies and practices (and the steps taken to institutionalize them) depends on whether the collaboration from which they emerge is deliberative and fully represents the available information and understanding of systems by stakeholders $[6,11,13]$. See for examples Breuer and Oswald Springs' contribution to this special issue [14]. The deliberation and representation of the available information not only enables a better understanding of the problem at hand and informs the development of effective measures [13,15], but it can also improve the legitimacy of collaboratively developed decisions [16-19]. Examples supporting this claim can be found in Gandhi and Johnson's contribution to this special issue [20].

\subsection{Defining Properties of Collaborative Governance}

Collaborative governance should be diverse. Scholars are in particular agreement that all stakeholders who could be affected or have a vested interest in the issue should be included in the decision process $[19,21,22]$. Efforts to include these perspectives in the collaborative process increase its legitimacy $[6,13]$.

It is also recognized that knowledge is scattered among several administrative levels and sectors [23,24]. Thus, it can only be fully utilized in polycentric settings, those that include representatives from the various decision centers that can drive or hinder desired change [15,16,24].

Likewise, two-way communication and dialogue is considered fundamental for the emergence and the success of collaboration $[13,23]$. Collaborative structures must be designed that enable mutual incorporation of expertise and of differing interests and values. Stakeholders should be able to exchange views and give each other feedback $[13,23]$. Scholars, who assess the relationship between participation and environmental outcomes, stress the importance of two-way information flows for capacity building among the stakeholders [25]. The sheer willingness for two-way communication is not sufficient, but rather must be exhibited, for such an outcome to develop [26]. In other words, collaborative governance should be deliberative. The here-presented case study observes a group of stakeholders, where the individuals refer to efforts to take all perspectives into account (e.g., use of facilitator) and describe the overall deliberation as open and fair and supportive of decision-making in a post-disaster situation.

Lastly, several scholars consistently warn that power imbalances within collaborative governance arrangements can undermine the success of these structures as a whole $[6,13,17,18,27,28]$. An unequal distribution of power is found to result in distrust and weak commitment, and to obstruct fairness, legitimacy and the efficacy of the decision-making process [6,13].

\subsection{Collaborative Governance in Post-Disaster Settings}

Researchers propose that measures must be taken to empower disadvantaged stakeholders, so that their interests also have a weight in discussions and decision-making processes $[10,13,28]$. The presence of ground rules and transparency is one such measure, as they ensure fairness and equity [13,25]. Such features also support social learning [29]. Clear communication rules can especially solve problems of power imbalance and/or co-optation [25]. Furthermore, the literature recognizes that facilitators can have a positive influence on interactions and communication between stakeholders, especially when disagreement or disputes occur $[13,28]$ Facilitators can also contribute to the fairness of the collaboration, not only helping with the establishment of ground rules but also balancing differences 
in power and preventing co-optation [25]. In order to have such an influence, the facilitator must be seen as "impartial, open to multiple perspectives and approachable" [25] (p. 2425). In the absence of clear ground rules, facilitators are expected to step up and mediate the agreement on such measures.

Scholars, who assess learning processes within adaptive co-management arrangements, underline that decision-making processes should strive toward consensus, recognizing that consensus processes can have positive outcomes by requiring stakeholders to come up with creative solutions [30]. Scholars also note that a consensus-oriented approach may not be appropriate in every situation, as it can be very sophisticated and time-consuming, or cause peer pressure [31]. Seeking consensus at all cost can also have negative consequences, as it may limit the diversity of interests and values represented [25]. Hence, successful collaborations can vary from top-down control to arrive at speedy decision-making on highly technical issues, to a bottom-up approach that uses, for instance, meaningful engagement with a wider set of stakeholders [6].

Communities that are more frequently affected by flooding are more likely to have already developed some or all of these measures to empower stakeholders [32]. Hence, the nature of the risk (such as a high probability of a recurrent flood) and a shared history of collaborative risk management (such as having collaborated on a prior flood) both increase the chance that collaborations will occur that represent all vested interests in a deliberative decision process [32].

In summary, studies of post-disaster collaborations should pay attention to (1) the diversity of a group, (2) the deliberation within a group, (3) the balance of power in a group, (4) the polycentricity of the group, (5) the ground rules that guide the group, (6) the group's reliance on a facilitator, (7) the meeting formats used, (8) the group's commitment to finding a consensus, (9) whether the group has a history of collaboration, and (10) the nature of the risk [33].

\subsection{Collaborative Governance after the 2016 Flash Flood in Braunsbach}

In this paper, we examine a collaboration after a flash flood that occurred in the municipality of Braunsbach on the 29 May 2016. The municipality is situated in the federal state of Baden-Württemberg, in the southwest region of Germany. The records for the day show precipitation of $153 \mathrm{~mm}$, with 131 mm accumulated in only two hours in the afternoon (between 4:00 and 6:00 p.m.) and with a maximum 5-minute intensity of $157 \mathrm{~mm} / \mathrm{h}$ [31]. This event was exceptional for the area, with the hotspot of the storm occurring over the catchment of the Orlacher Bach river, which passes by the villages Orlacher and Braunsbach.

The setting was selected for the following five reasons. First, climate change has increased the risk of extreme rain events occurring not just in the affected municipality but also in Baden-Württemberg in general. The storm that Braunsbach experienced in 2016 has been ranked with a return period above 100 years, highlighting the urgency of making changes to current flood-risk policies and practices in the region [31]. Second, Baden-Württemberg was highlighted as having developed a progressive flood-risk governance regime under the EU Floods Directive, with shortcomings in the area of learning that draws from multiple policy areas [32,33]; for example, the section assessing the flood risk for the state being unaware of potentially relevant expertise on the matter in another section of the state's administrative body. Third, the 2016 event constitutes a focusing event with the potential to activate advocates in different policy fields and trigger cross-group learning and substantial policy shifts [1]. The event highlighted, in particular, that severe thunderstorms that are generally of limited areal extent can cause flash floods in this and other small catchments in the area. Flash floods are defined as sudden floods with high peak discharges [1,34]. Flash floods can potentially be catastrophic in terms of damage and fatalities, and they have already destroyed key infrastructures, disrupted key services, and caused the loss of life all over the globe [35-39]. Fourth, a prior study highlighted the fact that the state's flood-risk assessment and subsequent flood management exhibited a focus on collaboration and an ability to adapt to new challenges [35,36]. Hence, it comes as no surprise that a task force was formed shortly after the event, to assess the risk and adjust mitigation efforts accordingly. Fifth, evaluations by independent technical experts suggest that the task force above initially did not pay 
sufficient attention to the potential risks associated with morphological changes and the transport of sediment and large woody debris ("large wood" hereafter) in the risk assessment and planning of mitigation measures [34,40-43]. Consequently, the municipalities' mitigation efforts were slow to take into consideration these aspects of the fluvial geomorphology.

These observations warrant the question of how the available expertise on the fluvial geomorphology for communities in Baden-Württemberg was represented in the collaboration after the 2016 flash flood in Braunsbach. To answer this question, we focused on the flow of information among the individual members of the task force that reviewed flood-risk assessment and management practices in Baden-Württemberg, in regard to the 2016 event. First, we surveyed the network through which these individuals sent and received information after the 2016 event. These ego-centric networks (social networks that form around a specific individual) can also be defined as individuals' learning spaces [33]. From these data, we can deduce information about the accessibility of specific guidance in the network that drives learning in the task force as a whole. In a second step, we summarize focus-group feedback, to better understand the presence and absence of specific interactions.

\subsection{Propositions}

This mixed-method approach will allow us to explore two propositions that we have deduced from the above-cited insights on collaborative governance in post-disaster settings.

Proposition 1. The expertise in some aspects of fluvial geomorphology is underrepresented in the post-disaster collaboration. To test the validity of this proposition, we ask whose perspective individuals in the collaboration accessed and how the presence of one individual's expertise in one person's learning space compares with the use of expertise in another learning space. We also look at deliberative interactions in individuals' learning spaces and ask how the learning spaces differ from one another in terms of these interactions. Finally, we explore the balance of power in each learning space, by examining whether individuals tend to focus on the expertise of specific individuals.

Proposition 2. Specific properties of a post-disaster setting can create or hinder opportunities to integrate aspects offluvial geomorphology, for example, in the collaboration that emerged after the flash flood in Baden-Württemberg. To test this proposition, we explore whether the study participants attribute differences in the inclusion or omission of specific expertise to any of the following seven qualities of the post-disaster collaboration: polycentricity, ground rules, facilitation, meeting size, consensus-oriented decision culture, nature of the risk, and history of collaboration.

\section{Materials and Methods}

We employed a mixed-method approach. First, we implemented a social network survey to assess the diversity, deliberation, and balance of power in individuals' learning spaces [44]. Second, we conducted a focus group (including a wish list, to obtain anonymous feedback), to identify aspects of the post-disaster setting that created and/or hindered the representation of the available expertise on specific aspects of fluvial geomorphology [33]. The qualitative evidence from the group discussion and wish list was used to verify and contextualize the individuals' survey feedback.

\subsection{Survey}

Social network analysis involves mapping network relations in various ways and applying a formal methodology to analyze them [45]. Hence, social network analysis offers the tools needed to identify and compare specific properties of the networks that underly a collaborative governance arrangement $[33,44]$.

In our study, we employed an ego-centric approach that captures from the individual's perspective information about the network underlying an observed governance arrangement. To achieve this, we asked an individual (denoted as Ego) to list all the contacts (denoted as Alters) with whom she had 
exchanged relevant information after the 2016 flash flood in Braunsbach, and additional questions specifying the affiliations (public, private, and non-governmental sector) of these contacts. Next, we asked our Ego whether and how frequently their Alters exchanged information that was relevant to the 2016 flash flood in Braunsbach.

A recent paper reviewed in depth the reliability of the survey tool that is employed in this research. It suggests that the first step, in which we asked an Ego to list all the Alters with whom she has exchanged relevant information after the 2016 flash flood in Braunsbach, produces moderately reliable data on an actual egocentric network structure. The second step, in which we asked our Ego whether and how frequently her Alters exchanged information that was relevant to the 2016 flash flood in Braunsbach, produced weakly reliable data [44].

Taken together, this information captured the ego-centric network of this survey participant (see Figure 1 for a visual example, in which the node shape denotes sector affiliation, smooth lines denote an inter-sector relationship, dotted lines denote an intra-sector relationship, and shading denotes the strength of the relationship, or frequency with which a pair interacted).

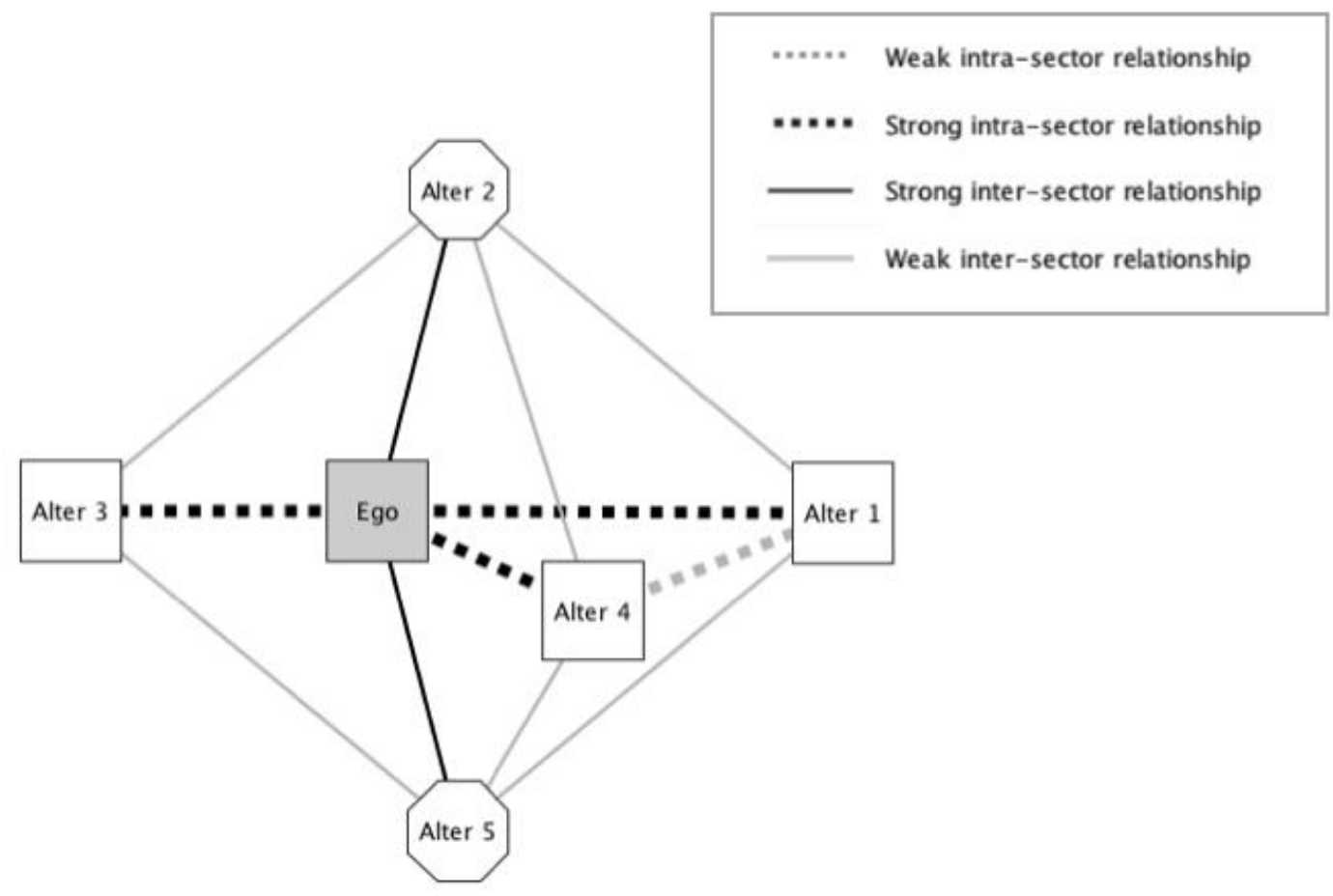

Figure 1. Example of an ego-centric network, showing also Alter-Alter connections.

Our network analysis of the data we collected in this manner consisted of two steps, as follows. First, we analyzed the similarities of the observed networks. Such an analysis provides insights about the integration of the different ego-centric networks that we captured with the survey. A high number of similar networks implies an integrated collaboration. Comparing networks for similarity also helps to identify networks that are only loosely connected to other networks. The individuals with the least-similar networks can be assumed not to be an integral part of the collaboration. To evaluate network similarity, we calculated the Szymkiewicz-Simpson's overlap coefficient for each combination of networks (see notes in Table 1 for details). Here we simply accounted for the number of actors that different networks have in common. In a related analysis, we calculated the percentage of ties held in common for Egos with overlapping networks. 
Table 1. Overlap between observed ego-centric networks: Szymkiewicz-Simpson's overlap coefficient.

\begin{tabular}{cccccccccc}
\hline $\begin{array}{c}\text { Ego-Centric } \\
\text { Network }\end{array}$ & $\begin{array}{c}\text { Count of } \\
\text { Actors in Net }\end{array}$ & GM1 & GS1 & GS2 & P1 & P2 & A1 & A2 & A3 \\
\hline GM1 & 9 & 1.00 & & & & & & & \\
GS1 & 12 & 0.33 & 1.00 & & & & & & \\
GS2 & 9 & 0.33 & 0.89 & 1.00 & & & & \\
P1 & 7 & 0.29 & 0.86 & 0.86 & 1.00 & & & \\
P2 & 6 & 0.50 & 1.00 & 1.00 & 0.83 & 1.00 & & & \\
A1 & 6 & 0.17 & 0.50 & 0.33 & 0.17 & 0.33 & 1.00 & & \\
A2 & 6 & 0.00 & 0.33 & 0.33 & 0.17 & 0.17 & 0.00 & 1.00 & \\
A3 & 14 & 0.11 & 0.25 & 0.22 & 0.00 & 0.17 & 0.33 & 0.33 & 1.00 \\
\hline
\end{tabular}

Szymkiewicz-Simpson's overlap coefficient. The score ranges from 0 (no overlap) to 1 (complete overlap). Let $|\mathrm{X}|$ be a list of Alters in a network $G_{1}$ of a specific Ego and $|Y|$ be a list of Alters in a network $G_{2}$ of a second, distinct Ego, then the overlap coefficient equals $|\mathrm{X} \wedge \mathrm{Y}| / \mathrm{min}(|\mathrm{X}|,|\mathrm{Y}|)$. Count of actors in net includes Ego and her Alters.

In a second step, we captured the defining properties of the networks that the survey participants identified [33]. The selected approach focuses on three structural properties: diversity of the represented interests, deliberation (the numbers of strong relationships present in the network), and the level of centralization (the balance of power within individuals' networks). To operationalize the first property, we counted all triads (e.g., the triad connecting Ego, Alter 3, and Alter 5 in Figure 1). Diversity was measured by counting the triads with intra-sectoral interactions (e.g., any triad in Figure 1). We compared this with the most diverse network possible, a network $\mathrm{G}$ with $n$ actors and $\alpha$ diverse groups of interest, where all possible diverse triads are realized. The maximum number of diverse triads can be calculated by the formula below (Equation (1)). If actors cannot be distributed evenly into $\alpha$ groups, the residual actors are split so that some groups differ in size by one actor. This approach is based on the assumption that the simultaneous presence of public, private, and non-governmental sectors in a network can serve as a proxy for the representation of diverse interests in the case studied.

With $n$ nodes and $\alpha$ subgroups of interest:

$$
\operatorname{Div}_{\max (G)}= \begin{cases}\frac{n !}{3 !(n-3) !} & , \text { if } n \leq 2 \alpha, \\ \frac{n !}{3 !(n-3) !}-\left(n \bmod \alpha \frac{\left\lceil\frac{n}{\alpha}\right\rceil !}{3 !\left(\left\lceil\frac{n}{\alpha}\right\rceil-3\right) !}\right) & , \text { if } 2 \alpha<n<3 \alpha, \\ \frac{n !}{3 !(n-3) !}-\left((\alpha-n \bmod \alpha) \frac{\left\lfloor\frac{n}{\alpha}\right\rfloor !}{3 !\left(\left\lfloor\frac{n}{\alpha}\right\rfloor-3\right) !}\right)-\left(n \bmod \alpha \frac{\left\lceil\frac{n}{\alpha}\right\rceil !}{3 !\left(\left\lceil\frac{n}{\alpha}\right\rceil-3\right) !}\right) & , \text { otherwise. }\end{cases}
$$

To operationalize deliberation, we captured the frequency with which any two individuals in our sample (see Section 2.1 Sample) interact (indicated by line thickness in Figure 1). The focus here was on intra-sectoral relationships (e.g., the relationship between Ego and Alter 3 in Figure 1).

Network centralization can be measured by using various indicators. We utilized variants of Freeman's [46] classic centrality measures-betweenness and degree centrality-as defined by Opsahl et al. [47]. These measures take into account the differences in edge strength, in our case, the frequency with which the surveyed Ego interacted with her Alters and the observed frequency with which Alters interacted with one another. The strength of our ego-centric approach is that it minimizes errors from missing data [48].

\subsection{Focus Group}

A focus group was conducted six weeks after the survey's start. Two independent observers recorded the behavior and word reactions of the group. An audio recording of the discussion was also taken (after making sure that no participant objected to the recording). One person facilitated the discussion.

Prior to the discussion, all participants in the focus group who had participated in the earlier survey received a sheet with a graphical representation of their individual Ego-network, as described in their survey reply. Respondents were then asked to comment on this graph and revise it (using a 
pen or pencil) during the course of the discussion, e.g., when they recalled another person of relevance. An example is given in Figure 2. The revisions were then explicitly used to verify the reliability of the survey tool [44].

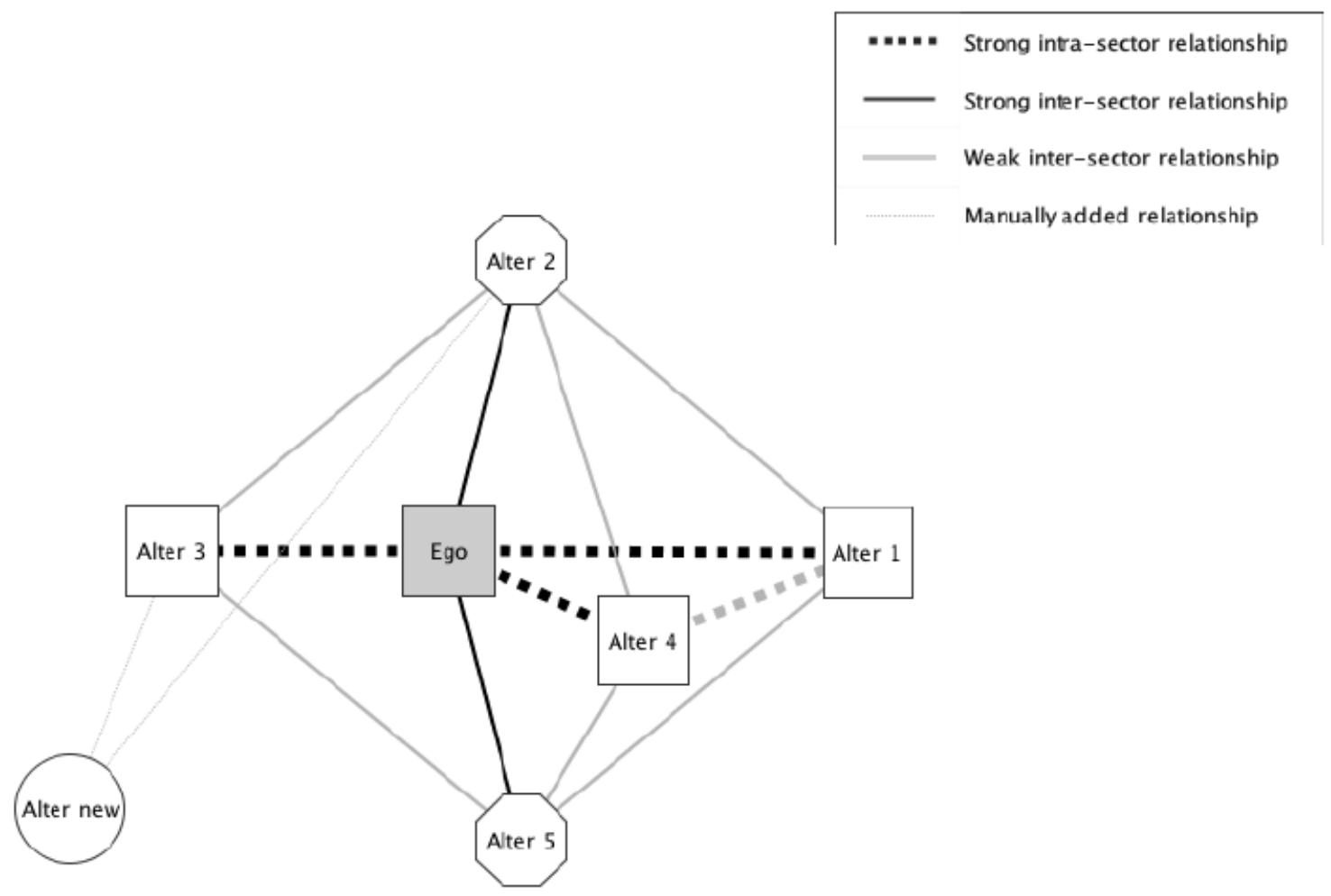

Figure 2. Example of a manual graph verification.

At the beginning of the group discussion, all the participants were asked to indicate their respective function in the months following the flash flood. In a follow-up question, participants were asked about their contacts and the relationships that helped them pursue their functions. At the end of the discussion, participants were asked to reflect on the factors that have enabled or hindered these interactions.

The main purpose of the focus group was to provide background knowledge that would help us interpret the survey findings. The analysis of the participants' feedback was limited by the focus-group method used, which is more structured than a mere group discussion, to ensure all participants' opinions on the properties of the post-disaster context are heard and discussed within the group [49]. In such a group setting, individuals would not necessarily repeat a point that they agree with when another person has already discussed it. This prohibits a statistical analysis for the focus-group data, such as exploratory factor analysis. Lacking also multiple readers to verify the current analysis of the German script, we decided to simply use quotations from the participants to exemplify what had been said or to provide a unique example. This is an accepted analysis technique in studies that rely on focus-group feedback to "corroborate quantitative findings" [50] (155).

\subsection{Wish List}

Prior to the focus-group meeting, a paper was circulated, and focus-group participants were invited to confidentially record wishes to improve factors in the current setup. The wish list offered an opportunity to state personal views that individuals would not necessarily want to share in a group setting. 


\section{Results}

The study focused on all individuals who contributed significantly to the evaluation of the flood in Braunsbach at the end of May 2016 and played a leading role in the planning and/or implementation of emergency and adaptation measures. A respondent-driven sampling approach [48] was used to identify these individuals, starting with the person in the public administration that attempted a coupling of three policy streams in order to utilize resources activated by the event to highlight and address shortcomings in the state's flood-risk management. This person then directly recruited the next seed, and so on. A total of 12 persons were recruited through this process in a total of three rounds and were surveyed in December 2018 and January 2019. Four of them took part in the survey before the focus group in January 2019, when their survey data could be fully verified. Two submitted the survey, but were represented at the focus-group meeting by another person. Two completed the survey on the day of or shortly after the focus group. Three did not submit a survey, two of which actively participated in the focus-group meeting and were included in the analysis presented here.

The final sample included ten individuals (see Table A1 in Appendix A for details): two municipallevel government representatives (GM), three representatives of the state of Baden- Württemberg (GS), two private consultancies (P), and three academics (A). With the exception of the first four individuals (GM1, GM2, GS1, and GS2), all of these individuals are technical experts. The collection of individuals demonstrates that the post-flood collaboration had access to knowledge of diverse aspects of the geomorphology in Baden-Württemberg, as well as expertise in the climatology and hydrology of extreme events, in particular landslides and morphological changes. The last individual on the list (A3) is a geomorphologist, who promoted the inclusion of morphological changes and large wood in the risk assessment following the event. This individual was actively involved in the research presented here and therefore only observed the focus-group discussion.

\subsection{Analysis: Survey}

Our analysis of the survey data consisted of two steps, as follows. First, we examined the overlap between survey participants; they were asked to list at least five individuals with whom they had exchanged information after the 2016 Braunsbach flood. The survey answers to this name-generating question returned a list of names for each Ego's network that varied in length from a minimum of six names to a maximum of 14 names. Our analysis reveals that the names on these lists overlap in almost all survey reports. The greatest overlap is observed between the reports of a private consultancy (P2) and a government representative of the state of Baden-Württemberg (GS2). Likewise, the networks of the two state actors overlap considerably. The state representatives are also a common contact for the academics that we surveyed, although the overlap between A1 and GS2 surpasses that of the other two academics. Noticeable is the low overlap between the academics' networks and between the networks of the private sector and the academic sector. Overall, the calculations in Table 1 suggest that the collaboration entailed an integrated core of state representatives and private consultants. In contrast, the municipal and academic networks were more loosely integrated in the collaboration that emerged after the 2016 flood in Braunsbach.

Next, our analysis examined the difference in ties among these overlapping actors (Table 2). Rather than just accounting for the presence of individual actors in any two networks, we took into consideration the strength of the observed relationships. We find that, taking relational weights into account, the Egos' reports about their interactions with their Alters, as well as their observations of interactions between their Alters, are highly consistent. Not only do we observe an integrated core, but we also find a consistent pattern of relationships that connect the Egos' networks to one another. Table 1 shows considerable overlap between the networks of all Ps and GSs. Upon closer inspection, we also find that these networks consist of similar relationships (Table 2). 
Table 2. Proportion of same ties among overlapping actors.

\begin{tabular}{|c|c|c|c|c|c|c|c|c|c|}
\hline $\begin{array}{l}\text { Ego-Centric } \\
\text { Network }\end{array}$ & $\begin{array}{c}\text { Count of } \\
\text { Links in Net }\end{array}$ & GM1 & GS1 & GS2 & P1 & P2 & A1 & A2 & A3 \\
\hline GM1 & 36 & 1.00 & & & & & & & \\
\hline GS1 & 35 & 0.92 & 1.00 & & & & & & \\
\hline GS2 & 36 & 1.00 & 0.89 & 1.00 & & & & & \\
\hline $\mathrm{P} 1$ & 16 & 1.00 & 0.88 & 0.88 & 1.00 & & & & \\
\hline P2 & 15 & 0.58 & 0.73 & 0.75 & 0.75 & 1.00 & & & \\
\hline A1 & 13 & 0 & 0.67 & 0.50 & 0 & 0.75 & 1.00 & & \\
\hline $\mathrm{A} 2$ & 15 & 0 & 0.75 & 0.75 & 0 & 0 & 0 & 1.00 & \\
\hline A3 & 42 & 0 & 0.50 & 0.25 & 0 & 0 & 1.00 & 0.75 & 1.00 \\
\hline
\end{tabular}

In a second step, we looked at the defining properties of the networks that the survey participants identified, starting with the analysis of centralization in the individuals' networks. The lack of star-shaped networks, reflected in the low network centralization values recorded for each network in Table 3 (found using Freeman's indicators [46]), suggests that all surveyed Egos perceive themselves as part of an integrated network. In other words, they do not report that information between individuals in their network primarily flows through them, but rather that they maintain contact to individuals who also interact with another. In fact, the networks of three individuals (GM1, GS2, and A2) are fully connected-all the individuals in each of the three networks are directly linked to another individual. Hence, these individuals have very similar centrality values. This also holds true when taking the relational strength into account (an indicator defined by Opsahl et al. 2010 [47]). In contrast to our general finding, the network of A3 constitutes the extreme opposite on this spectrum. The high centralization score for A3's network implies an imbalance of power. In other words, only a few Alters in the network of A3 share a connection.

Table 3. Low ego-network centralization, indicating balance of power in the observed ego-centric networks.

\begin{tabular}{|c|c|c|c|c|c|c|c|c|}
\hline Centralization Indicators & GM1 & GS1 & GS2 & P1 & P2 & A1 & A2 & A3 \\
\hline $\begin{array}{l}\text { Freeman's degree } \\
\text { centralization (i) }\end{array}$ & 0 & 0.24 & 0 & 0.33 & 0 & 0.2 & 0 & 0.63 \\
\hline $\begin{array}{l}\text { Freeman's betweenness } \\
\text { centralization (ii) }\end{array}$ & 0 & 0.27 & 0 & 0.33 & 0 & 0.04 & 0 & 0.34 \\
\hline $\begin{array}{l}\text { Gini coefficient (iii) based } \\
\text { on Opsahl's degree } \\
\text { centrality (iv) }\end{array}$ & 0.06 & 0.14 & 0.02 & 0.16 & 0 & 0.14 & 0.08 & 0.25 \\
\hline
\end{tabular}

(i) The values of betweenness and degree centralization presented here are based on Freeman (1978) [46]. (ii) With few exceptions, all the calculations of the degree and betweenness centralization withstood the CUG tests. A CUG test renders graphs (using a Monte Carlo simulation), keeping either the number of edges or the size constant, and applies the statistic of interest [51]. Replicated numerous times, the resulting distribution indicates whether the condition alone is a likely cause of the measurement result. In a CUG test of betweenness, of 10,000 replications, $99.9 \%$ scored lower than our observed graph, for degree $97.7 \%$ of the simulated networks. Therefore, we can be confident that the effect is not a mere artifact springing from size or edge count. The exceptions are the networks of GS1, P1, and A1, where size may have had an effect on the degree centrality. (iii) Gini coefficient represents dissimilarities of the centrality values for the individuals in any given ego-network [47]. The higher the coefficient, the higher the difference in the centrality values of the network members. When applied to the concept of centralization, a high Gini coefficient indicates high levels of centralization. (iv) To apply Opsahl's et al. weighted centrality measure, one chooses a tuning parameter between 0 and 1 , determining how much link strength increases the value of a certain edge between nodes [47]. While this parameter can be chosen arbitrarily, 0.7 (assuming relational strength to be important) has proven to be a reasonable value to use.

Next, we analyze the diversity in the individuals' networks. Here, we looked at the number of inter-sector and intra-sector relationships, focusing on fully connected triadic structures (e.g., the connections between Ego, Alter 3, and Alter 5 in Figure 1) in which at least two sectors are represented. Here, again, we observe that two out of three individuals (GM1, P2) with well-integrated 
networks (see Table 3) also display highly diverse networks. In this group of diverse networks also fall the networks of the Egos GS2 and P1, where we see between 60 and 70 percent of inter-sector triads. The group of least-diverse networks is made up of the academic networks and the network of GS1. Here, as in the analysis above, the network of A3 exhibits the highest number of non-diverse intra-sector relationships. In other words, the network of A3 lacks diversity.

The values presented in Table 4 do not take into consideration the strength of the inter- and intra-sector ties. We therefore also conducted an analysis that compared the frequency of contact between inter- and intra-sectoral relationships (Table 5), to establish deliberation in the individuals' networks. The results indicate no noticeable difference. Furthermore, we observe that the academics rarely interacted with others during the period studied. On average (median), we record between 1-3 times a year (median score 3) and 1-3 instances of interaction since the event in 2016 (median score of 2). In contrast, governmental representatives interact with others on average between 1-3 times a month (median score of 4) and 1-3 a year (median score of 3). It is noteworthy that the survey participants complained about there not being an option in the survey to select quarterly meetings.

Table 4. Diversity: count of diverse triads in the observed ego-centric networks.

\begin{tabular}{ccccccccc}
\hline Diversity Scores & GM1 & GS1 & GS2 & P1 & P2 & A1 & A2 & A3 \\
\hline $\begin{array}{c}\text { Inter-sector (proportion } \\
\text { diverse triads) }\end{array}$ & 76 & 98 & 49 & 24 & 16 & 9 & 10 & 131 \\
$\begin{array}{c}\text { Intra-sector } \\
\text { (non-diverse triads) }\end{array}$ & 5 & 110 & 32 & 10 & 4 & 11 & 10 & 209 \\
Max possible triads & 81 & 208 & 81 & 34 & 20 & 20 & 20 & 340 \\
\hline
\end{tabular}

Table 5. Inter-sector versus intra-sector deliberation.

\begin{tabular}{ccccccccc}
\hline Ego-Centric Network & GM1 & GS1 & GS2 & P1 & P2 & A1 & A2 & A3 \\
\hline Inter-sector & 3 & 3 & 4 & 4 & 3 & 2 & 2 & 3.5 \\
Intra-sector & 4 & 3 & 4 & 4 & 3 & 3 & 2 & 3 \\
Overall & 4 & 3 & 4 & 4 & 3 & 3 & 2 & 3 \\
\hline
\end{tabular}

See Section 2, Materials and Methods, for formula upon which this calculation is based.

We used an R-code that looped through all networks and computed simple descriptive statistics (mean, median) for (a) overall links of the networks, (b) homophile/intra-sector links, and (c) heterophile/inter-sector links. Neither mean nor median seem to vary meaningfully. This table only presents the median values.

\subsection{Analysis: Focus Group}

Survey participants also attended a focus-group discussion. Feedback from this discussion helped us to understand the observed similarities and the differences in factors that drive or hinder efforts to access the collaboration. Key statements from the focus group can be found in Section 4 . Here, we give a brief summary (see also Table 6).

Table 6. Contributions to focus group by participant (as per transcript).

\begin{tabular}{ccccccccccc}
\hline Statements & GM1 & GM2 & GS1 & GS2 & GS3 & P1 & P2 & A1 & A2 & Total \\
\hline Statements count & 5 & 10 & 9 & 6 & 3 & 2 & 3 & 2 & 3 & 43 \\
$\quad \begin{array}{c}\text { Word count } \\
555\end{array}$ & 1147 & 1270 & 358 & 463 & 367 & 86 & 149 & 184 & 4579 \\
$\begin{array}{c}\text { Percent by word } \\
\text { contributions }\end{array}$ & $12 \%$ & $25 \%$ & $28 \%$ & $8 \%$ & $10 \%$ & $8 \%$ & $2 \%$ & $3 \%$ & $4 \%$ & $100 \%$ \\
\hline
\end{tabular}

As mentioned in the section introducing our sampling procedure and sample, attending the focus group were two individuals whose survey feedback was not received (due to time and technical 
issues) but who were well represented in the Egos' networks. These individuals are a government representative of the federal state (GS3) and a representative of the municipality (GM2). Two other individuals were represented at the meeting but did not attend themselves: a representative of a private consultancy (P1) and an academic (A1).

As stated above, the discussion was moderated by a facilitator, and each participant was prompted to respond to a set of open questions. In general, contributions varied between the individuals in terms of the number of occasions that a statement was made and the length (word count) of the statement.

Most of the statements from the focus-group discussion that are quoted in Section 3.3, below, indicated the speakers' positive sentiment. To verify that this indication reflects the tone of the discussion as a whole, we conducted a quantitative sentiment analysis for the transcript as a whole (word by word). This analysis suggests a tendency for using positive words (as defined in the dictionary of positive and negative sentiments) in the statements made by the focus-group participants (see Table 7), such as together, coordinated, appreciated, constructive, easy, engaged, honest, and accessible. We conclude from this that the participants judged their collaboration in positive terms overall. Negative sentiments found in the transcript were generally used in a context that still communicated a positive meaning, such as "nothing personal" (German: "das ist jetzt nicht böse gemeint").

Table 7. General sentiment recorded for the discussion (translation).

\begin{tabular}{|c|c|}
\hline $\begin{array}{l}\text { Extreme Negative Sentiments Observed } \\
\text { in Transcript }(\mathrm{N}=10)\end{array}$ & $\begin{array}{l}\text { Extreme Positive Sentiments Observed in Transcript } \\
\qquad(\mathrm{N}=41)\end{array}$ \\
\hline $\begin{array}{l}\text { e.g., "cumbersome", "hard" "unclear", } \\
\text { "missing", "exclusive", "random", } \\
\text { "strenuous", "mean", "unwanted", } \\
\text { "worried" }\end{array}$ & 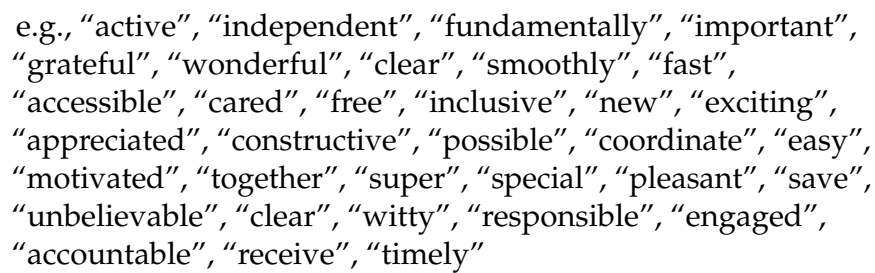 \\
\hline
\end{tabular}

Sentiment analysis conducted in $\mathrm{R}$ (tidyverse), based on the following dictionary: https://github.com/flovv/SentimentScoring/blob/master/Senti/SentiWS_v1.8c_Negative.txt.

\subsection{Wish List}

While an effective facilitation of a focus group can ensure that unpopular views are heard, or at least take a record of participants' nonverbal responses (such as sounds of agreement or disagreement), we also gave the option to write down feedback on matters that need to be improved and submit it anonymously to the facilitator. This option was labeled a "wish list". Everyone was asked to submit such a wish list, to ensure anonymity.

The majority of points raised on these lists confirm the time pressure that the participants were under to make substantial decisions and the strain of taking time to commute to meetings. Several individuals wished that, in the future, they would have time to consider the expertise in greater detail before making such substantial decisions. Proposed solutions were additional investments in technical solutions to record on-site observations and communicate them to the network in a timely manner.

\section{Discussion}

The available evidence at the time of this study implied that the window of opportunity and new information presented by the flood had been used to refine calculations for flood risk in small catchment areas by including the role of sediment, but that the impact of large wood and morphological changes had not been paid sufficient attention. These observations motivated our research into the question of how the available expertise on these aspects of fluvial geomorphology for communities in Baden-Württemberg was represented in the collaboration that arose to develop a response to the Braunsbach flood. More specifically, we explored the two propositions, P1 and P2, defined before, to wit, as follows: 
P1. The expertise in some aspects of fluvial geomorphology is underrepresented in the post-disaster collaboration.

P2. Specific qualities of a post-disaster setting can create or hinder opportunities to integrate aspects of fluvial geomorphology, for example in the collaboration that emerged after the flash flood in Baden-Württemberg.

In theory, a post-disaster deliberation that includes diverse interests and is perceived as fair and open would facilitate information exchange and thus individual learning. The survey findings show that the majority of individuals in the collaboration identify their learning spaces as well-integrated, diverse, and not very centralized settings. One counter example is that, with the exception of A1, individuals appeared in general not to learn from $A 3^{\prime}$ s expertise on large wood. In order to verify and contextualize the survey data, we conducted a focus group, to identify factors that appear to have contributed to the fact that some, but not all, of the available scientific expertise was included in the deliberation. Next, we analyze the 10 categories defined in Proposition 2's explanation, at the end of the introduction, before we integrate the entire analysis.

\subsection{Collaboration in General}

Focus-group participants emphasized their dependency on the expertise of one another, which motivated them to reach out to one another. Immediately after the event, GM1 and his network explored measures to protect the community, while GM2 managed the communication with the public. During this process, questions arose concerning the nature of the risk at hand, the most effective solutions to decrease Braunsbach's vulnerability to flooding, and what state-level support the community could rely on (GM1, FG transcript 3: 09.55). GM1 took these questions to GS1 and, in doing so, triggered a search for information at the state level, where individuals realized that they too did not fully understand the risk and implications of the flood hazard.

We see in the survey data that a closely integrated information exchange developed between P1, P2, GS1, and GS2. According to the focus group, GS3 was also a central element in this core structure and responsible for bringing P1 into the discussion. Central to this group information exchange were the risks associated with morphological changes and sediment transport. Roughly one year later, GS1 initiated facilitated meetings, to incorporate the lessons learned from this event into the governance structure that deals with flood-risk management in the state of Baden-Württemberg. It seems fair to conclude that GS1's ability to attach the post-flood collaboration to the formal flood-risk management process ensured the institutionalization of the expertise gained since the event.

Not part of this emerging core collaboration are the Egos who represent the municipality, who managed the situation on the ground and reported their observations back to actors operating at the state level.

Orbiting around the core collaboration is the group of academics, who entered the scene to survey the phenomenon shortly after the first media reports. The fact that these scholars were nominated during the sampling process and that their research was cited by core members during the focus-group discussion implies that core members value their work. However, the survey data also suggests that the scientific expertise was not a central part in the deliberation.

Least well integrated are A3's efforts to better understand and incorporate the issue of large wood in the risk assessments. This individual's learning environment shows primarily affiliations with academics and students, neither of which possess strong connections to the core collaboration that connects the two clusters above. It is noticeable that $\mathrm{A3}^{\prime} \mathrm{s}$ expertise on the effects on large wood in flooding was only mentioned by A1 during the focus-group discussion, and this could be due to the lack of diversity in $\mathrm{A3}^{\prime}$ s network.

\subsection{Diversity}

In general, information was sought out from people who "deal with such topics all the time" (translation of GS3, FG transcript 3: 04.47): technical experts who pursue scientific questions; engineering offices who plan and manage the filtering structures; official participants who enable the 
implementation of the plans via advisory services (and have access to data, financing, and information on legal framework conditions); and construction companies who implement the measures on site. "These different categories-I think-we have-we try to connect with each other" (translation of GM2, FG transcript 3: 05.52). Governmental representatives from the state and municipal level agree that the initially high pressure from the community that followed the emergency drove communication efforts; in their words, "the pressure ultimately starts with the community" (translated from GM1, FG transcript 3: 10.43).

Their search for information uncovered first and foremost existing sources of information within the administration (GS1, FG transcript 3: 16.38). These new points of contact then recommended private consultancies (GS1, FG transcript 3: 19:29). In their search, the state representatives relied on structures that were naturally there, such as the collaboration that dealt with the heavy rain hazard prior to the 2016 event, and sources of information recommended via a professional link. In contrast, the elected representative of the municipality necessarily mediated between experts and residents, especially, as in the instance of the Braunsbach flood, when public attention was very high in regard to flood-risk mitigation efforts on the ground. This included attention from academic experts in the field of sediment movement who traveled to the area after seeing media coverage. GM2 emphasized that the "scientific contributions were important", in that they highlighted disadvantages of certain measures, such as building a dam at the upper part of the catchment (translation of GM2, FG transcript 3: 18:26) that would not have effectively mitigated the risks associated with sediment movement. In the same statement, GM2 also recognized the importance of feedback from the construction companies, concerning the feasibility of specific flood-risk measures (translation of GM2, FG transcript 3: 18:26), for example, the feasibility in terms of the available local resources.

In general, the networks of governmental representatives were more diverse than that of the academics and private consultants. GM1's network was characterized by low centralization and the highest levels of diversity. As stated above, GM1 coordinated actions on the ground, to decrease the vulnerability of Braunsbach to flooding. The focus-group feedback also suggests that state-level representatives identified GM1 as a primary contact for the academics. Within this group, GS2 reported a fully connected network with the least variations in Opsahl's degree centralization (see Table 3) and fairly high levels of diversity (see Table 4). From the focus-group discussion, we learn that GS2's role was to connect the different levels of decision-making.

In contrast, the academic networks captured with the survey exhibit low levels of diversity. As stated above, A3's network was the least-diversified structure (see Table 4). The reported information exchange implies high levels of centralization (see Table 3) that is indicative of a classic academic structure (supervising research or conducting research in collaboration with other researchers). The survey data imply a lack of inter-sector interactions. This is likely to have hindered efforts to penetrate the core and place the issue of large wood on the agenda. It seems that A2, an expert on the geomorphology of the region, was more successful in this regard. Of all the academics surveyed, A2's learning environment included the highest number of inter-sector triads. The latter's survey data indicate high levels of integration and moderate levels of diversity. During the focus-group meeting, several participants confirmed that they worked with A2, who supervised transdisciplinary student projects focused on sediment movement related to the event.

\subsection{Polycentricity}

In Germany, flood risks are assessed at the state level, while municipalities lead the implementation of flood-risk measures and emergency response. An effective flood-risk management thus requires an effective vertical exchange of information. It also requires parallel learning at each level of administration. The survey data support the conclusion that the collaboration connected the municipal and state level of decision-making. In addition, the focus-group discussion positively emphasized that the collaboration connected not only the vertical but also the horizontal levels of decision-making, with each individual taking the lead in the area of their expertise. For example, the municipal 
representatives who participated in our study managed construction measures with locals (GM1, FG transcript 3: 10.43). Technical and legal questions were deliberated at the state level (GS1, FG transcript 2: 02.10-05:46).

\subsection{Deliberation}

Evidence from the survey suggests that the frequency of contact did not vary when a relationship in the post-flood collaboration crossed-sectoral boundaries. Within learning environments that have been identified as diverse, this suggests an optimal environment for deliberation and learning, as ideas are not circulating in a homogenous group. According to the focus-group participants, their interactions have been fair and open and have resulted in high levels of trust between the collaborators. All group members believe the post-disaster communication processes to have been fair and open (e.g., A1, FG transcript 3: 22:34, P2, FG transcript 3: 08.21). They also expressed their belief that "collegial respect" (GS3, FG transcript 3: 04.47), "mutual collegial esteem" (GS1, FG transcript 3: 06.24), and "constructive cooperation" (translation of P2, FG transcript 3: 08.21) actually facilitated the flow of information between one another. "We don't need a hierarchy ... at the moment [we have] a very good cooperation" (translation of G3, FG transcript 3: 04.47). When prompted to explain this level of trust in one another, they highlighted that they motivated each other through their professionalism and commitment to their task(s). "Everyone was aware of where their counterpart's competences lie" (translation of GS3, FG transcript 3: 04.47). This point was echoed by all participants, in regard to their inter-sectoral and intra-sectoral interactions.

While there was no doubt about the fairness of the communication process and the advantage of being able to bounce ideas off someone, the group agreed that deliberation was limited by time constraints, due to the urgency of the issue. More specifically, the uncertainty about the cause of the flash flood, which raised questions about the risk of another flash flood occurring and about the correct and most feasible response. "Ideally, one would have 1-2 years for the deliberation" (translation of GM2, FG transcript 3: 9:55). The lack of time seems to not have negatively impacted the deliberation process.

\subsection{Clear Ground Rules}

The abovementioned trust evidently emerged from an informal tit-for-tat approach, grounded in professional courtesy and collegial esteem. The focus-group participants saw others give their best in their respective realm of expertise and felt committed to match these efforts themselves (GS1, FG transcript 3: 04:07), within a "professional code of conduct" (GS3, FG transcript 3: 04:07), for example, deliver action points on time and as agreed. The result was the absence of a "hierarchical structure, since everyone is an expert in their category" (translation from GM2, FG transcript 3: 05.52).

Focus-group participants also recognized that the collaboration was successful, because this trust in each other allowed them to operate slightly ahead of the formal process (e.g., work was started before everything was sealed on paper), as people stayed true to their word (GS2, FG transcript 4: 06:24). It is also noteworthy that these comments were not only made in relation to contacts that collaborators knew prior to the 2016 event and their affiliates. As one academic recalls, they also found kind citizens, when arriving at the scene, who responded to their requests for information (A1, FG transcript 3: 22:34).

There were few counter examples of individuals positively framing these interactions. Only the governmental representatives addressed the transaction costs of communication, recognizing that the integration of the communication structure requires a great deal of communication effort from all sides.

\subsection{Consensus-Driven Approach}

While the evidence shows the commitment of the post-flood collaboration to a fair and open inter-sector deliberation that enhances the adaptivity of the state's flood-risk management, there seems to be no evidence that members were committed to a consensus-based approach. In fact, a lack of time 
to regard all perspectives fully was noted during the focus-group discussion (GM2, FG transcript 3: 9:55). Lack of time was also mentioned multiple times on the wish list. It seems that the surveyed governmental representatives favor a top-down approach of decision-making, relying primarily on the advice of affiliated experts (e.g., P1 and P2) to arrive at speedy decisions on highly technical issues. While the focus-group data imply that meaningful engagement did not occur with every individual whom the surveyed Egos identified as relevant (and that our analysis revealed were, in fact, placed at the fringe of the discussion), the focus-group feedback and wish list do not suggest that these insights were intentionally excluded to silence their particular point of view. Rather, their exclusion was the result of the urgency of the decision-making at hand.

\subsection{Facilitator and Hosting Meetings at a Variety of Scales}

Confirming the group's commitment to a fair and open deliberation are positive comments about the use of a neutral facilitator and facilitating techniques during their meetings. The use of a facilitator or techniques to facilitate discussions in the critical orientation phase ensures "that something comes out without you getting lost in the technical side" (GS1, FG transcript 3: 02:45). While nobody specifically emphasized the positive effect of having meetings at a variety of scales, multiple statements confirm that the group approached broader topics with larger meetings and more specialized issues with smaller meetings.

\subsection{Balance of Power}

Focus-group participants described the collaboration as an aggregation of highly integrated hierarchical structures that are led by expertise rather than a formal decision process. This is revealed by low levels of centralization in the individual networks (see, e.g., low centralization scores for GS1 and P2 in Table 3). With the exception of the high level of centralization in A3's network, information generally flows through many individuals.

\subsection{History of Collaboration}

The survey findings imply that the core of the observed collaboration is well integrated. The focus-group feedback suggests that the core's membership consists of pairs of individuals who have collaborated in the past. For example, GS3 knew of P1 as a geological expert and, when approached by GS1 and GS2, integrated this expertise with the expertise of P2. Together, the data suggest that the deliberation focused on contacts within established governance structures, while only loosely regarding the group of academics at its fringe.

\subsection{Nature of the Risk}

Focus-group participants agreed that Braunsbach was a special case. The existing problems and the media attention were concentrated on a single municipality; therefore, it was not a situation where multiple municipalities had to compete for resources (such as technical expertise and funding).

Braunsbach was a special situation on the part of the state. One participant observed that, in "my professional life", no other municipality received as much attention and resources after a flood event as Braunsbach. The participant goes on explaining this phenomenon with the narrow impact radius of the flash flood (only one municipality was affected). A wider impact radius would have resulted in a greater number of municipalities and, subsequently, competition between the municipalities for resources (translation of GS1, FG transcript 4: 12:52).

Focus-group participants suggested that the severity of the flash flood put the water-related disaster on the public and political agenda. As one participant explained, in a new situation, adrenaline, emotions, and forces are released that cannot be maintained for years. They are only mobilized in such a situation (GS1, FG transcript 3: 16.38). The political attention following the Braunsbach flood presented an opportunity for the state representatives, under the leadership of GS1, to activate resources to create new structures that will take effect in the event of another flash flood. This special post-disaster setting 
also helped individuals to overcome instances where pre-event advocacy (e.g., for environmental protection) hindered the implementation of a flood-risk measure, such as the removal of a tree from a river (GS2, FG transcript 3: 13.04).

Our analysis of the focus-group transcript also finds that the academics traveled to the scene shortly after the disaster, attracted by media coverage about the event. This is a noteworthy point, since scientific scrutiny was not invited. Scientists were drawn to the event and took steps to join the collaboration after the emergency entered the public agenda and attracted media attention. This involvement of the scientific community has ultimately ensured that the core group of individuals collaborating on the flood response is aware of alternative perspectives.

However, focus-group participants also reported a lack of time to stop and reflect on whether the deliberation actually represented all the available expertise. The survey data suggest, in particular, a bias toward established expertise within the administration or their affiliations (contracted private consultants). In other words, the severity of the event forced decision makers to rely on established experts.

\subsection{Incorporating Expertise in the Collaboration: Known Drivers and Barriers}

Our research confirms that a well-integrated and diverse core of relationships between governmental representatives and private consultants who specialize in hydrology and sediment movement emerged at the heart of the observed collaboration. Deliberation with members of this core group has been widely regarded as fair, open, and driven by collegial esteem. The group not only utilizes the available resources to support the municipal actors in their efforts to secure their community, but also has triggered the revision of the existing flood-risk planning for the state of Baden-Württemberg. Central here is the institutionalization of the lessons learned after the 2016 flash flood in Braunsbach. The plans that emerge from this will take into account the impact of sediment transport during flash floods and help to prepare at-risk communities in small catchments, such as Braunsbach.

Academic insights, notably expertise on the contribution of morphological changes and large-wood-to-flood hazard, were not an integral part of this post-disaster deliberation, resulting in the development of less-resilient flood-management measures in Braunsbach. This is not to say that the expertise was ignored. Members of the core collaboration were linked to this fringe group of academics and were aware of the academics' work, and thus recommended that their expertise would be surveyed in the course of the study presented here [2-4,6]. With regard to the first proposition of our research (i.e., the representation of the available expertise on the aspects of fluvial geomorphology in the deliberation), we therefore conclude that, in an emergency context, academics who possess fewer contacts with local stakeholders and less collegial esteem than other participants in the collaboration are less likely to be included in the deliberation. In this context, the focus of the collaboration is on established expertise and their affiliations.

While hindering the inclusion of the available academic insights in core activities, the emergency itself attracted media coverage and scientific scrutiny. This resulted in a short but intense exchange of information between governmental representatives and experts, whose expertise was recommended by shared affiliations (e.g., individual A knew B and C before the flood and recommended B to C after the flood). The development of a core group within the post-flood collaboration was supported by a professional facilitator and the small size of the group. The core's commitment to fully incorporating the available expertise on fluvial geomorphology in Baden-Württemberg, coupled with the risk-driven bias toward established expertise, explains the presence of loose ties between the core and fringe groups. With regard to the second proposition examined in our study (i.e., concerning the factors that impact the representation of specific expertise in the collaboration), we conclude that variations in the inclusion of specific expertise in post-flood deliberations can be explained by the high-risk setting, which required quick and informal responses from the decision makers. 


\section{Conclusions}

We can conclude that our mixed-method approach generated evidence supporting the propositions that motivated our study. Experts on fluvial geomorphology were underrepresented in the post-disaster collaboration, but core members recognized the importance of these ideas (demonstrated, for example, by their inclusion of the experts surveyed in this study) and showed a commitment of the study participants to collaborative decision-making, exhibited by study participants reporting an open and fair dialogue during the focus-group discussion.

We used an innovative survey approach to systematically map the networks of municipal-level government representatives, representatives of the state of Baden-Württemberg, private consultancies, and academics that together entered a collaboration in response to the 2016 Braunsbach flood [39]. By employing this method, we were able to identify that the academics occupied a fringe position in the otherwise well-integrated network. We also noticed differences in the level of integration of each academic, with A2 being more integrated than A3. From the focus-group discussion, we learned that A2 had a history of collaboration with members at the core, whereas A3 did not. Furthermore, the focus-group discussion and wish list highlight that lack of time and pressure from the public were two factors that biased the deliberation process and effectively hindered academics from further exploiting the window of opportunity that collaborative efforts opened after the disaster. More specifically, the post-disaster setting did not favor deliberative interactions in a large group context. It is an accomplishment that weak relationships between the core and the fringe group were established and maintained after the event.

Our method does exhibit certain limitations. Our commitment to respondent-driven sampling meant that we did not capture the post-flood collaboration in its entirety, as our Egos decided who to recruit to the survey. The group they recruited was smaller than the full list of Alters in their networks. Most noticeably, we missed the engineering firms, construction firms, the first responders (e.g., the fire brigade), and the residents who interacted with the academics during their inquiry. Our analysis also would have benefited from a series of interviews in which network members were asked about the information they received from a particular contact and what they learned from this information. Currently, we can only assume that frequent contact translates to learning and the adoption of new ideas in a policy context. Lastly, there is the problem of memory. Our analysis assumes that all participants are in a position to recall all the relevant contacts they have relied upon since the event, although it has been 30 months since the event itself. Despite these limitations, our research has increased understanding of post-disaster collaboration, and has set the stage for further research.

Our study was only made possible because natural scientists approached social scientists about this case, and state funding was made available to pursue this inquiry. Furthermore, our research was carried forward by the enthusiasm and willingness of the municipal and state actors to participate in our study. Further research is needed that includes more such points of contact and resources for new collaborations, to truly understand changes in socioecological systems. This will aid governing bodies in developing their means to face challenges related to water disasters.

Author Contributions: The research was supervised by C.Z., managed by A.L., conducted and written-up by A.W. with the support of F.B. All authors have read and agreed to the published version of the manuscript.

Funding: This research was supported by the Water Research Funding Program and the Brigitte Schlieben Lange Programm, both with funds from the Ministry of Sciences, Research and the Arts, Baden-Württemberg.

Acknowledgments: We acknowledge support by Open Access Publishing Fund of University of Tübingen.

Conflicts of Interest: We have no conflict of interest to declare. 


\section{Appendix A}

Table A1. Study Participants.

\begin{tabular}{ccc}
\hline Label & Participated Survey & Participated Focus Group \\
\hline GM1-Municipality & Yes & Yes \\
GM2-Municipality & No & Yes \\
GS1-State & Yes & Yes \\
GS2-State & Yes & Yes \\
GS3-State & No & Yes \\
P1-Private Contractor & Yes & Appointed a representative \\
P2-Private Contractor & Yes & Yes \\
A1-Independent Academic & Yes & Appointed a representative \\
A2-Independent Academic & Yes & Yes \\
A3-Independent Academic & Yes & Took part as an observer \\
\hline
\end{tabular}

\section{References}

1. Birkland, T. Natural Disasters as Focusing Events: Policy Communities and Political Response. Int. J. Mass Emergencies Dis. 1996, 14, 221-243.

2. Woldesenbet, W.G. Collaborative governance: Assessing the problem of weak cross-sectoral collaborations for the governance of Addis Ababa Rivers. Appl. Water Sci. 2018, 8, 74. [CrossRef]

3. Zahariadis, N. Ambiguity and Multiple Streams. In Theories of the Policy Process, 3rd ed.; Sabatier, P.A., Weible, C.M., Eds.; Westview Press: Boulder, CO, USA, 2014; pp. 25-58.

4. Cairney, P.; Zahariadis, N. Multiple streams approach: A flexible metaphor presents an opportunity to operationalize agenda-setting processes. In Handbook of Public Policy Agenda Setting, 1st ed.; Zahariadis, N., Ed.; Edward Elgar Publishing Limited: Cheltenham, UK, 2016; pp. 87-105.

5. Jones, B.D.; Baumgartner, F.R. From there to here: Punctuated equilibrium to the general punctuation thesis to a theory of government information processing. Policy Stud. J. 2012, 40, 1-19. [CrossRef]

6. Emerson, K.; Nabatchi, T.; Balogh, S. An Integrative Framework for Collaborative Governance. J. Public Adm. Res. Theory 2012, 22, 1-29. [CrossRef]

7. True, J.L.; Jones, B.D. Punctuated equilibrium theory. In Theories of the Policy Process, 1st ed.; Sabatier, P.A., Weible, C.M., Eds.; Westview Press: Boulder, CO, USA, 1999.

8. Baumgartner, F.R.; Green-Pedersen, C.; Jones, B.D. Comparative studies of policy agendas. J. Eur. Public Policy 2006, 13, 959-974. [CrossRef]

9. Kemper, L.; Partzsch, L. Saving Water while Doing Business: Corporate Agenda-Setting and Water Sustainability. Water 2020, 11, 297. [CrossRef]

10. Chief, K.; Meadow, A.; Whyte, K. Engaging Southwestern Tribes in Sustainable Water Resources Topics and Management. Water 2016, 8, 350. [CrossRef]

11. Kim, H.; Son, J.; Lee, S.; Koop, S.; van Leeuwn, K.; Choi, Y.J.; Park, J. Assessing Urban Water Management Sustainability of a Megacity: Case Study of Seoul, South Korea. Water 2018, 10, 682. [CrossRef]

12. Tuson, J.; Triebskorn, R. Civil Society and the Governance of Water Services: German Political Parties' Reactions to Right2Water. Water 2020, 12, 1-16.

13. Ansell, C.; Gash, A. Collaborative Governance in Theory and Practice. J. Public Adm. Res. Theory 2008, 18, 543-571. [CrossRef]

14. Breuer, A.; Oswald Spring, U. The 2030 Agenda as Agenda Setting Event for Water Governance? Evidence from the Cuautla River Basin in Morelos and Mexico. Water 2020, 12, 314. [CrossRef]

15. Pahl-Wostl, C. Transitions towards adaptive management of water facing climate and global change. Water Resour. Manag. 2006, 21, 49-62. [CrossRef]

16. Pahl-Wostl, C. A conceptual framework for analysing adaptive capacity and multi-level learning processes in resource governance regimes. Glob. Environ. Chang. 2009, 19, 354-365. [CrossRef]

17. Emerson, K.; Nabatchi, T. Collaborative Governance and Collaborative Governance Regimes. In Collaborative Governance Regimes, 1st ed.; Public Management and Change Series; Emerson, K., Nabatchi, T., Eds.; Georgetown University Press: Washington, MA, USA, 2015; pp. 14-36. 
18. Emerson, K.; Nabatchi, T. Initiating Collaborative Governance: The System Context, Drivers, and Regime Formation. In Collaborative Governance Regimes, 1st ed.; Public Management and Change Series; Emerson, K., Nabatchi, T., Eds.; Georgetown University Press: Washington, MA, USA, 2015; pp. 39-56.

19. Pells, C. Power and the Distribution of Knowledge in a Local Groundwater Association in the Guadalupe Valley, Mexico. In Collaborative Governance Regimes, 1st ed.; Public Management and Change Series; Emerson, K., Nabatchi, T., Eds.; Georgetown University Press: Washington, MA, USA, 2015; pp. 136-156.

20. Gandhi, V.P.; Johnson, N. Enhancing Performance of Participatory Water Institutions in the Eastern Indo-Gangetic Plains: What Can We Learn from New Institutional Economics and Governance Theories? Water 2020, 12, 70. [CrossRef]

21. Johnston, E.W.; Hicks, D.; Nan, N.; Auer, J.C. Managing the Inclusion Process in Collaborative Governance. J. Public Adm. Res. Theory 2011, 21, 699-721. [CrossRef]

22. Vangen, S.; Hayes, J.P.; Cornforth, C. Governing Cross-Sector, Inter-Organizational Collaborations. Public Manag. Rev. 2015, 17, 1237-1260. [CrossRef]

23. Berkes, F. Evolution of co-management: Role of knowledge generation, bridging organizations and social learning. J. Environ. Manag. 2009, 90, 1692-1702. [CrossRef]

24. Weiss, K.; Hamann, M.; Kinney, M.; Marsh, H. Knowledge exchange and policy influence in a marine resource governance network. Glob. Environ. Chang. 2012, 22, 178-188. [CrossRef]

25. Newig, J.; Challies, E.; Jager, N.W.; Kochskaemper, E.; Adzersen, A. The Environmental Performance of Participatory and Collaborative Governance: A Framework of Causal Mechanisms. Policy Stud. J. 2018, 46, 269-297. [CrossRef]

26. Renn, O. Participatory processes for designing environmental policies. Land Use Policy 2006, $23,34-43$. [CrossRef]

27. Niles, M.T.; Lubell, M. Integrative Frontiers in Environmental Policy Theory and Research. Policy Stud. J. 2012, 40, 41-64. [CrossRef]

28. Reed, M.S. Stakeholder participation for environmental management: A literature review. Biol. Conserv. 2008, 141, 2417-2431. [CrossRef]

29. Tippett, J.; Searle, B.; Pahl-Wostl, C.; Rees, Y. Social learning in public participation in river basin management-early findings from HarmoniCOP European case studies. Environ. Sci. Policy 2005, 8, 287-299. [CrossRef]

30. Armitage, D.; Marschke, M.; Plummer, R. Adaptive co-management and the paradox of learning. Glob. Environ. Chang. 2008, 18, 86-98. [CrossRef]

31. Dalton, T.M. Exploring Participants' Views of Participatory Coastal and Marine Resource Management Processes. Coast. Manag. 2006, 34, 351-367. Available online: https://ien.arch.virginia.edu/publications/ collaboration-guide-environmental-advocates-uva-2001 (accessed on 23 February 2020). [CrossRef]

32. Albright, E.A.; Crow, D.A. Learning Processes, Public and Stakeholder Engagement: Analyzing Responses to Colorado's Extreme Flood Events of 2013; American Political Science Association: Washington, MA, USA, 2014; pp. 1-29.

33. Witting, A.; Brandenstein, F.; Kochskämper, E. Evaluating Learning Spaces in Flood Risk Management in Germany: Lessons for Governance Research. J. Flood Risk Manag.. under review.

34. Bronstert, A.; Agarwal, A.; Boessenkool, B.; Fischer, M.; Heistermann, M.; Köhn-Reich, L.; Moran, T.; Ozturk, U.; Reinhardt-Imjela, C.; Wendi, D. Forensic hydro-meteorological analysis of an extreme flash flood: The 29/05/2016 event in SW Germany. Sci. Total Environ. 2018, 630, 977-991. [CrossRef]

35. Newig, J.; Kochskaemper, E.; Challies, E.; Jager, N.W. Exploring governance learning: How policymakers draw on evidence, experience and intuition in designing participatory flood risk planning. Environ. Sci. Policy 2016, 55, 353-360. [CrossRef]

36. Newig, J.; Schulz, D.; Jager, N.W. Disentagling Puzzles of Spatial Scales and Participation in Environmental Governance-The Case of Governance Re-scaling Through the European Water Framework Directive. Environ. Manag. 2016, 58, 998-1014. [CrossRef]

37. International Association for Hydrological Sciences. Flash Floods. In Proceedings of the Paris Symposium; IAHS-UNESCO-WMO, Ed.; International Association for Hydrological Sciences: Wallingford, UK, 1974; Volume 112.

38. Jonkman, S.N. Global Perspectives on Loss of Human Life Caused by Floods. Nat. Hazards 2005, 34, 151-175. [CrossRef] 
39. Doocy, S.; Daniels, A.; Murray, S.; Kirsch, T.D. The human impact of floods: A historical review of events 1980-2009 and systematic literature review. PLoS Curr. 2013, 16, 29. [CrossRef] [PubMed]

40. Borga, M.; Comiti, F.; Ruin, I.; Marra, F. Forensic analysis of flash flood response. WIREs Water 2019, 6, e1338. [CrossRef]

41. Laudan, J.; Rözer, V.; Sieg, T.; Vogel, K.; Thieken, A.H. Damage assessment in Braunsbach 2016: Data collection and analysis for an improved understanding of damaging processes during flash floods. Nat. Hazards Earth Syst. Sci. 2017, 17, 2163-2179. [CrossRef]

42. Lucía, A.; Schwientek, M.; Eberle, J.; Zarfl, C. Planform changes and large wood dynamics in two torrents during a severe flash flood in Braunsbach, Germany 2016. Sci. Total Environ. 2018, 640, 315-326. [CrossRef]

43. Ozturk, U.; Wendi, D.; Crisologo, I.; Riemer, A.; Agarwal, A.; Vogel, K.; López-Tarazón, J.A.; Korup, O. Rare flash floods and debris flows in southern Germany. Sci. Total Environ. 2018, 626, 941-952. [CrossRef] [PubMed]

44. Witting, A.; Brandenstein, F.; Shato, K. Hidden knowledge brokers and their informants: Introducing an egocentric and respondence driven analysis in a public service context. Environ. Policy Gov. 2020, 20, 1-13.

45. Newig, J.; Fritsch, O. Environmental governance: Participatory, multi-level and effective? Environ. Policy Gov. 2009, 19, 197-214. [CrossRef]

46. Freeman, L.C. Centrality in Social Networks: Conceptual Clarification. Soc. Netw. 1979, 1, $215-239$. [CrossRef]

47. Opsahl, T. Triadic Closure in Two-Mode Networks: Redefining the Global and Local Clustering Coefficients. Soc. Netw. 2010, 35, 159-167. [CrossRef]

48. Perry, B.L.; Pescosolido, B.A.; Borgatti, S.P. Egocentric Network Analysis: Foundations, Methods, and Models; Cambridge University Press: Cambridge, UK, 2018.

49. Institut für Zukunftsstudien und Technologiebewertung. Die Fokusgruppen. Methode als Instrument in der Umwelt- und Nachhaltigkeitsforschung (Werkstatbericht Nr. 82). Available online: https://www.izt.de/fileadmin/ publikationen/IZT_WB82.pdf (accessed on 6 April 2020).

50. Wiggins, G.S. The Analysis of Focus Groups in Published Research Articles. Can. J. Program Eval. 1993, 19, 143-164.

51. Butts, C.T.; Carley, K.M. Some Simple Algorithms for Structural Comparison. Comput. Math. Organ. Theory 2005, 11, 291-305. [CrossRef] 